\title{
A droga da subversão: anticomunismo e juventude no tempo da ditadura ${ }^{1}$
}

The Drug of Subversion: Anti-Communism and Youth in the Time of the Dictatorship

Antonio Mauricio Freitas Brito*

\section{Resumo}

Amparado no uso de acervos repressivos, o artigo explora representações anticomunistas difundidas pela comunidade de segurança e informações, que associaram o uso de drogas a uma estratégia do movimento comunista internacional para corromper a juventude durante a ditadura. Essa acusação se vinculava a uma tradição anticomunista conspiracionista atualizada pela Guerra Fria e pelos protestos juvenis nos anos 1960/1970, impactada pela modalidade repressiva transnacional da guerra às drogas desenvolvida pelos Estados Unidos. Esses elementos convergiram com argumentos do probicionismo que tomavam a droga como o fantasma do mal vinculado à destruição da família e à devassidão moral-sexual. Por isso, alguns documentos sobre a toxicomania comunista no Brasil modelaram essa percepção. Em paralelo ao pânico anticomunista, a repetição do argumento não esteve fundamentada em evidências. Essas frações inflacionaram o perigo vermelho, instrumentalizando-o para demarcar posições políticas ao longo da ditadura militar.

Palavras-chave: Anticomunismo; ditadura; juventude; drogas; proibicionismo.

\section{Abstract}

Supported by the use of repressive collections, this article explores anti-communist representations spread by the security and information comunity, which associated the use of drugs with a strategy of the international communist movement to corrupt youth during the dictatorship. This accusation was linked to an anti-communist conspiracy tradition updated by the Cold War and by youth protests that took place in the 1960s/1970s, which was impacted by the transnational repressive modality of the war on drugs developed by the United States. These elements converged with prohibition arguments that considered drugs the phantom of evil linked to the destruction of the family and to moralsexual debauchery. For this reason, some key documents on communist drug addiction in Brazil shaped this perception. Parallel to the anti-communist panic, the repetition of the argument was not based on evidence. These fractions inflated the red danger by instrumentalizing it to demarcate political positions throughout the military dictatorship.

Keywords: Anti-Communism; dictatorship; youth; drugs; prohibition.

\footnotetext{
* Universidade Federal da Bahia (UFBA), Salvador, BA, Brasil. mafbrito@hotmail.com <https://orcid. org/0000-0002-7570-1632 >
} 
O ano de 1973 não parecia ser promissor. Ao menos é o que sugere o documento confidencial produzido pela agência central do Serviço Nacional de Informações (SNI). O papel secreto afirmava que a "toxicomania" era "uma das mais sutis e sinistras armas do variado arsenal do [Movimento Comunista Internacional] MCI [...] em sua busca contínua e subreptícia pelo domínio do mundo e escravidão da humanidade" (Ministério da Justiça..., 1973, p. 2). Essas lições teriam sido incorporadas pela Tricontinental de Havana - um evento de Solidariedade dos Povos da África, da Ásia e da América Latina ocorrido em Cuba (1966) e considerado o mais influente encontro internacional dos anos 1960 fora do oeste ocidental (Young, 2018). A Tricontinental teria aprovado a "desmoralização da juventude, por meio do estímulo ao consumo de alucinógenos” (Ministério da Justiça..., 1973, p. 2), pois a droga aceleraria a revolução. Os viciados fariam tudo a favor do movimento revolucionário em troca da droga. Para o SNI, estava em curso um "fortalecimento extraordinário do MCI" que reunia "condições de empregar recursos [...] legais ou clandestinos, pacíficos ou violentos, morais ou amorais" (Ministério da Justiça..., 1973, p. 8).

Também em 1973, uma operação policial foi desenvolvida na Universidade de Brasília (UnB) esquadrinhando a vida de trinta e três moradores de residências da instituição (Lima, 2017). Acusados de "pederastas" e "viciados", aqueles jovens supostamente viviam em um "antro de corrupção de costumes" e "acentuada promiscuidade, onde tóxicos e sexo [...] [eram] misturados com impregnação ideológica de esquerda” (Ministério do Exército..., 1973, p. 23). Para a polícia, a vida estudantil nas repúblicas era marcada por um baixo índice de limpeza. Atualizando a ideologia da higiene em voga no século XIX e a noção de que "toda a experiência de guerra [Fria] é, antes de tudo, experiência do corpo" (Audoin-Rouzeau, 2011, p. 365), o documento "censurava corpos" endereçando a sujeira aos jovens barbudos e cabeludos. Além da estética transgressora e da pederastia - termo pejorativo para designar relações homoeróticas -, as atividades artísticas, o erotismo e o sexo "desregrado e quase grupal" comprovavam para aqueles policiais a estratégia dos comunistas "em utilizar a corrupção dos costumes, como auxiliar do binômio tóxico-subversão" (Ministério do Exército..., 1973, p. 30).

As duas fontes sobre a toxicomania comunista se inserem em uma tradição anticomunista construída no Brasil desde o século XIX. Nutrida com mais vigor após a Revolução Russa (1917), essa tradição originou "um conjunto de representações [negativas] sobre o comunismo, um verdadeiro imaginário anticomunista" (Motta, 2002, p. XXII). O anticomunismo pode ser designado 
como uma "oposição sistemática ao comunismo ou aquilo que é a ele identificado, uma oposição que se adapta a diferentes realidades e se manifesta por meio de representações e práticas diversas" como "produção de propaganda, controle e ação policial” (Rodeghero, 2002, p. 464).

Apesar da pouca evidência empírica, a acusação das drogas como estratégia comunista não é novidade na historiografia. No final dos anos 1970, Comblin (1978) identificou o tema no pronunciamento de militares das Américas. Ana Lagôa (1983) encontrou registros com este teor no SNI. Gilberto Velho (1987) refletiu sobre esse sistema de acusação empregado durante a ditadura brasileira. Coimbra (1995) analisou a problemática a partir do discurso psicologizante da "crise da família". Após incursão nos arquivos repressivos, Brepohl de Magalhães (1997) descobriu a problemática em um documento do DOPS Paraná. Motta (2002) apontou como o repertório anticomunista incluiu essa questão. $\mathrm{O}$ mesmo vale para pesquisas sobre as "comunidades de segurança e informação" e a censura (Fico, 2001; 2002). Sem perder de vista a importância destas contribuições, a problemática exige ser investigada.

Ampliando o diálogo com uma historiografia mais recente, e amparado em documentos produzidos pelo Serviço Nacional de Informações, pela Polícia Federal, pelo Centro de Inteligência do Exército e pelo Centro de Informações e Segurança da Aeronáutica - entre outros órgãos repressivos -, este artigo demonstra a acusação das drogas como estratégia comunista esquadrinhando seus argumentos, em interlocução com uma abordagem atenta à subversão delimitada "em termos morais e sexuais" (Cowan, 2012, p. 404), ao mesmo tempo se inspirando numa história das "representações culturais e políticas de repressão [às drogas]" (Carneiro, 2018, p. 19). A toxicomania comunista foi um argumento construído por frações civis e militares durante a ditadura. No contexto da Guerra Fria, essas representações reproduziam uma tradição anticomunista moral e conspirativa atualizada pela chamada "revolução nos costumes". Esses elementos alimentaram uma reação contrassubversiva e conservadora, convergindo com as moralidades em torno do proibicionismo, que associava a droga à promiscuidade sexual e à destruição da família.

Sexo, Drogas E SUbVersão: UM PLANO MUNDIAL DOS COMUNISTAS

As representações discutidas neste artigo circularam principalmente em redes secretas e evidenciam a "intromissão abusiva do Estado em assuntos privados, como o uso de substâncias psicotrópicas e a sexualidade” (Brandão, 
2019, p. 114). Rastreadas a partir de documentos pesquisados no Arquivo Nacional (Distrito Federal), elas foram elaboradas principalmente por homens socialmente brancos pertencentes às "comunidades de segurança e de informações” - uma estrutura formada pelo SNI e outros órgãos repressivos. De acordo com Fico (2001, p. 21), seus membros militares se especializaram na construção de "um campo de produção e de circulação de mensagens relativamente autônomo" que comportava "muito de autoconvencimento por retroalimentação" (Fico, 2001, p. 21, 100) para inculcar valores e modelar atitudes. A repetição de conteúdos para formar opinião era nutrida também por noções anticomunistas de crise moral elaboradas por uma tecnocracia da Escola Superior de Guerra (ESG), em interlocução com autoridades religiosas e psiquiatras, bem como com acadêmicos, operadores jurídicos e grupos de extrema-direita articulados transnacionalmente (Cowan, 2016).

Esses sujeitos apresentavam demandas. Uma circular apresentou insatisfações quanto à "falta de recursos humanos e materiais necessários a que esses órgãos enfrent[e]m eficazmente o perigo” (Ministério do Exército..., 1981, p. 6) comunista e desempenhem suas atribuições satisfatoriamente. De acordo com outro documento, "os órgãos que combatem o comunismo têm de ser subvencionados, assim como o são os apoiados pela URSS e seus satélites” (Subversão, Terrorismo..., s/d, p. 2). Portanto, essas fontes representavam expectativas por reconhecimento, apoio material e poder por parte destas comunidades que se consideravam dotadas de autoridade e legitimidade para falar em nome dos ideais da "Revolução de 1964" e do combate a tudo que consideravam ação subversiva. Difundiram sistematicamente as supostas estratégias dos comunistas, operavam pela teoria do complô e se viam como as forças da pureza da revolução (Girardet, 1987). Em alguns momentos, tentaram disputar essa agenda publicamente, principalmente através da imprensa.

A toxicomania como estratégia comunista está em descompasso com memórias e trabalhos que indicam que os comunistas e a esquerda tinham uma atitude severa e/ou depreciavam o uso de drogas, associando-as à fuga, à alienação e ao desbunde (Almeida; Weiss, 1998; Risério, 2005; Muller, 2013; Dunn, 2014; Kaminski, 2017; Delmanto, 2015; 2018). Ainda que a questão mereça pesquisas englobando a diversidade de organizações de esquerda e que atentem a eventuais especificidades regionais e geracionais, é nítido o contraste com as representações anticomunistas, que "hipertrofiavam" o "valor de uso" e o "valor de signo" (Carneiro, 2018, p. 24-5) das drogas junto aos comunistas. Por essa razão, as sensações descritas por um pesquisador do pensamento das comunidades de informações são análogas à percepção que tivemos ao ler os 
documentos analisados: “a primeira reação é o riso. A preocupação com a força do inimigo parece excessiva; o jargão dos militares envolvidos empresta aos documentos um tom grandiloquente e tecnicista de algum modo incompatível com a real dimensão do problema". Além disso, "o tratamento ideológico é de tal forma precário, que soa como o mais elementar 'falseamento da realidade"' (Fico, 2002, p. 72).

É legítimo descrever o "sabor do arquivo" (Farge, 2009), mas é insuficiente tomar essa sensação como explicação. O antropólogo Gilberto Velho (1987) ressaltou o uso da categoria subversivo para "estigmatizar as pessoas de esquer$d a$ " naquele contexto, bem como a ideia de subversivo associada à ameaça, ao perigo e à violência. "Drogado" era uma acusação moral, médica e política, pois "o problema de drogas aparece associado a um plano subversivo de origem externa para minar a juventude brasileira [...]. A idéia é que a droga enfraquece a moral". Isso possibilita que "as categorias de drogado e subversivo possam aparecer emparelhadas. [...] Surge o subversivo-drogado, que é perigosíssimo, pois encarna todos os males" (Velho, 1987, p. 60-61), emergindo como uma categoria estigmatizadora, ou seja, "um atributo profundamente depreciativo" (Goffman, 1975, p. 13). As acusações alimentavam o medo da "subversão comunista" nutrido por "noções convencionais de moralidade" presentes nas estratégias de controle do uso da maconha e no estereótipo do viciado (Becker, 2008, p. 82).

$\mathrm{O}$ anticomunismo no Brasil representou os comunistas como imorais ou amorais, destruidores da família e corruptores dos costumes (Motta, 2002). A isso deve ser conectada uma reação conservadora ao que parecia ser a desestruturação das relações sociais com a construção da República (1889), acompanhada de ameaças aos "jovens castos" como o homossexualismo, o vício das drogas e a prostituição (Rago, 1996). Plínio Salgado (1949, p. 164) alimentou preocupação com a pornografia e com o "bolchevismo que pretende destruir as [...] famílias”. Nos anos 1950, a dança, a música e os bailes viraram moda juvenil, trazendo apreensão a alguns segmentos sociais (Pinsky, 2014). Nesta longa duração, o conservadorismo dos costumes foi mobilizado em conexão com noções de família, gênero e moral. Esses aspectos convergiram com a história internacional das regulações morais sobre o uso das drogas, com base no argumento da destruição da família nuclear e da devassidão moral (Carneiro, 2018).

A atmosfera da Guerra Fria e da contracultura trouxe novos ingredientes a essa tradição anticomunista, conservadora e proibicionista. O pânico da guerra nuclear, a emergência da juventude como uma categoria social singular 
e a disputa polarizada entre EUA e URSS pela hegemonia mundial marcaram aquela cena (Delmanto, 2018). Sensibilidade/estilo de vida que emergiu nos Estados Unidos e Europa entre os anos 1960 e 1970, a contracultura circulou pelo mundo, sendo que alguns países latino-americanos "testemunharam movimentos vibrantes de contracultura, que estavam ligados a processos transnacionais através da circulação de textos, música, cinema” (Dunn, 2014, p. 434). Naquele contexto, "o recurso à alteração de consciência buscada por meio do uso de psicodélicos e drogas em geral, ilícitas ou em vias de se tornarem, assume um papel importante dentro dos ideais de contestação" (Delmanto, 2018 , p. 24). Isso foi impactado pela maneira como alguns grupos contraculturais lidaram com as drogas nos EUA.

O ano de 1968 é emblemático por compreender a profusão destas representações. Interpretado como a "primeira rebelião global", o "longo anos sessenta" viu emergir protestos estudantis e greves de trabalhadores, novas ideologias e contraculturas em diferentes latitudes, contextos e culturas que "estavam ligados por uma rede densa de conexões transnacionais, reais e imaginárias, desejadas por muitos e temidas por muitos outros" (Klimke; Nolan, 2018, p. 1). Havia o receio de a rebelião afetar os comportamentos, os afetos e as dinâmicas de sociabilidade. Sirinelli (2014, p. 50) afirmou que "a guerra é sempre uma poderosa fábrica de estereótipos”. Com a Guerra Fria não foi diferente. Além da lógica binária de produção de estereótipos negativos sobre os comunistas, os temores se relacionavam com a abertura das portas da percepção por meio dos alucinógenos, da psicodelia, da contracultura, do rock'n roll, da busca da autonomia juvenil, da revolução sexual, do movimento hippie. Termos como contracultura, comunista e hippies foram inflacionados (Delmanto, 2018), designando indiscriminadamente sujeitos e práticas contestatórias amplas. A imprensa, o livro, as revistas, o cinema e a música ajudaram a difundir essas cenas. A percepção da Escola Superior de Guerra (ESG) era de que os meios de comunicação de massa em consolidação pareciam dotados de um poder uniformizador, pois parte dos jovens brasileiros tenderia a copiar os padrões de comportamento dos países centrais (Duarte, 2016, p. 16). Além de eleger a problemática dos "Meios de Comunicação Social", articulada com a "Desagregação da Família”, a "Problemática da Juventude" e a "Liberação da Mulher", teóricos moralistas identificaram uma vaga noção de contracultura como o "problema fundamental do mundo ocidental e do Brasil", igualando subversão, violência, guerrilha, terrorismo com cultura hippie e contracultura (Cowan, 2016, p. 117-119).

A circulação dessas imagens modelou o período como uma das conjun- 
turas mais transnacionais do século XX, codificada por preocupações locais (Manzano, 2014b, p. 253), em meio às "conexões conspiratórias" (Langland, 2018, p. 21): a convergência de algumas aspirações nos protestos globais foi lida por frações anticomunistas como evidência de um plano para destruir a civilização ocidental. Nesta "lógica da suspeição" (Brepohl de Magalhães, 1997), a contracultura, o movimento hippie, o feminismo, o antirracismo e o comunismo eram sinônimos. No Brasil, a contracultura foi vista como "artimanha criada pelo comunismo soviético", os hippies teriam sido criados por Moscou (Kaminski, 2017, p. 467); o movimento negro era "mais um elemento da ação comunista no país” (Kössling, 2007, p. 36). O antifeminismo também temperou a gramática anticomunista que percebia o feminismo como o emblema da destruição da família e da decadência moral (Alves, 2020).

Essa disputa atualizou o conspiracionismo. De acordo com Knight (2003, p. 15), as teorias da conspiração atribuem a uma suposta conspiração desenvolvida por um grupo secreto a culpa por um estado indesejável de coisas. Nenhum acontecimento é aleatório, mas sim responsabilidade de alguém com má intenção que o planejou. Essa chave de leitura, típica da tradição anticomunista, foi atualizada naquela conjuntura polarizada. A visão conspirativa anticomunista postulava que não havia acaso: os atores agiam pelo cálculo do conflito, o outro fazia sempre escolhas racionais e a moral era objeto de disputa política - variante da estratégia psicossocial construída pela Doutrina de Segurança Nacional (DSN), um dos vetores que animou o anticomunismo moral (Cowan, 2016).

As imagens veiculadas de uma revolução comportamental pautada por jovens geraram mal-estar em diversos setores apoiadores da ditadura. Braghini (2015) demonstrou os medos e perigos que ameaçavam a juventude, segundo segmentos conservadores. No caso militar, Chirio (2012, p. 121) afirma que "temas de destruição da família, da derrubada da moral e dos estragos provocados pelo materialismo ateu não eram, até 1968, centrais nas declarações públicas de militares [brasileiros]". Rememorando 1968 no Brasil, o Brigadeiro Burnier comentou que os "subversivos" estariam "bastante enxertados das idéias [...] sobre amor livre”. Além disso, "todos eles drogados [...] se imiscuíram dessas idéias [...] [que] começaram a perturbar a mocidade brasileira [...]. E a prova disso foi o $30^{\circ}$. Congresso da UNE [...]. Era uma fazenda alugada pela UNE onde jovens, moças e rapazes, faziam amor livre na vista de todos, tomavam drogas, um verdadeiro bacanal, uma coisa estúpida" (D’Araujo, 1994, p. 209-210). Essa visão está presente no Orvil - documento produzido por setores do Exército para disputar a memória sobre o período -, que reite- 
ra o Congresso da UNE como um evento no qual "foram encontradas drogas, bebidas alcoólicas e grande quantidade de preservativos” (Orvil, s.d., p. 228). Estes exemplos sinalizam como o discurso da toxicomania foi se relacionando com as construções de gênero e a politização da moral e do sexo (Rubin, 2012). Afinal, ideias de masculino e feminino estavam sendo disputadas desde o golpe de 1964, ilustrando as mobilizações do gênero (Duarte, 2011) e as batalhas pelo gênero (Langland, 2008).

\section{A PROFUsÃo dE REPRESENTAÇÕES SOBRE}

A TOXICOMANIA COMUNISTA

A narrativa acusatória do Orvil não poupou a resistência armada. Numa passagem, afirma-se que "durante cerca de 20 dias, 33 militantes transformaram o que seria o I Congresso Nacional da VAR-P num festival de bebedeiras e tóxicos" (Orvil, s.d., p. 393). A imprensa não ficou imune a esse tipo de pronunciamento. O Chefe do Serviço de Informações do DEOPS/SP denunciou que "o indivíduo que se vicia torna-se presa mais fácil para o terror, pois suas barreiras mentais e morais ficam debilitadas" (Gasparotto, 2008, p. 151). Já o General Fernando Bethlem alertou que havia "um fundo ideológico no tráfico de tóxicos no País, através do interesse dos comunistas em corromper as mentes jovens, para destruí-las, bem como à nossa sociedade cristã" (Abreu, 2000, p. 137). O Correio Braziliense afirmou que "as autoridades qualificaram o problema dos tóxicos e entorpecentes no País como da mesma gravidade que a eliminação do terrorismo" (Brandão, 2019, p. 111).

Outro militar associou drogas e luta armada: "a prisão de terroristas [...] [demonstrava] que agiam, nos assaltos e outros atos insanos, sob a ação excitante das drogas" (Abreu, 2000, p. 137). Mais de uma década depois, o "10 painel Subversão, terrorismo e narcotráfico na América Latina” considerou que os tóxicos liberavam o comportamento humano necessário para o terrorismo, e que a droga "proporciona[va] condições favoráveis à ação subversiva, sendo por isso, sustentada pelo MCI” (Subversão, Terrorismo..., s/d, p. 1). O pressuposto comum a este argumento é não reconhecer racionalidade na resistência armada. As drogas proporcionariam a alteração no estado de consciência necessária para ato tão "insano". Vale lembrar que esses documentos não apresentam evidências que comprovem o argumento.

É difícil saber quem eram os mais vulneráveis às drogas aos olhos destes agentes repressivos. Em 1970, o General Carlos Murici publicizou dados dos 
presos políticos: 56\% eram estudantes ou egressos da condição estudantil; entre esses, a média de idade era de 23 anos; 20\% eram mulheres; no Rio de Janeiro, em 1969, 80\% dos presos estavam no $1^{\circ}$ ano da Universidade; em São Paulo, 90\% dos presos estudavam na Faculdade de Filosofia (Jornal do Brasil, 1970, p. 5). O pronunciamento do militar, somado a outras fontes, sugere qual o público percebido como ameaça e/ou tido como potencialmente subversivo: estudante ou recém-egresso, na faixa etária entre 15 e 25 anos, branco, de classe média, com alguma capacidade de consumo, intelectualizado e crítico dos padrões culturais (Marcelino, 2011; Brito, 2019). Essa hipótese é reforçada a partir de Cowan $(2012 ; 2016)$. Ao estudar uma tecnocracia moral ligada à Escola Superior de Guerra (ESG), o autor concluiu que o foco do anticomunismo moralista era a juventude de classe média tida como alicerce do equilíbrio da nação, lugar onde se enfraquecia a estrutura familiar e terreno da promiscuidade.

Resta saber se os agentes policiais acolhiam estas ideias. Joffily (2013, p. 195-196) descreve o caso envolvendo um suspeito de tráfico de LSD, preso em São Paulo, pela Delegacia Especializada em Entorpecentes, e encaminhado à Operação Bandeirantes. O ofício que descreve o episódio alude a uma carta suspeita de subversão encontrada com um indivíduo; menciona que, na sua residência, havia livros subversivos. Não houve alusão ao tráfico de drogas como estratégia subversiva. Para pensar um pouco sobre a recepção desta abordagem, uma pessoa presa por porte de LSD durante a ditadura afirmou que "tinha uns caras que falavam [...] que era parte de um complô internacional para destruir a juventude brasileira. E o DOPS [...] os policiais [...] achavam muito engraçado porque eles sabem o que é bandido [...]. Mas a polícia que tava atrás da subversão era uma outra polícia, não era polícia civil era [...] uma conjugação de uma polícia política, que era o DOPS mais Exército, Marinha e Aeronáutica” (Delmanto, 2018, p. 267).

Outro exemplo para pensar em que medida a toxicomania comunista orientou a repressão ao consumo de drogas é uma entrevista feita em 1972 com o Inspetor Nelson Duarte, lotado no Rio de Janeiro. "Detetive que ficou famoso em todo o país, através da televisão, como o inimigo número um das drogas", o policial foi alvo de reportagem associando drogas a hippies, a homens de cabelos compridos, a "viciados envenenados e mortos pelas drogas [como] Jimi Hendrix, Janis Joplin" e a "som que se fala e faz por aí. Só tem barulho e muitas vezes provoca o entorpecimento" (Rolling Stone, 1972, p. 13). Não há nenhuma menção à conspiração comunista, o que sugere a necessidade de se pesquisar o impacto dessas representações nas Secretarias de Segurança Pública, nas Delegacias Especializadas em Entorpecentes e nas demais instâncias policiais. 
Estimava-se que 5\% dos jovens corriam risco de dependência na zona sul do Rio de Janeiro (Garcia, 1972). Em 1966, um recenseamento feito pela Comissão Nacional de Fiscalização de Entorpecentes identificou "850 mil viciados em tóxicos", sendo "395 mil” pelo uso de drogas “e o restante por alcoolismo" (Graça, 1971, p. 64). O autor reconhece que "as estatísticas sobre tóxicos são extremamente falhas, pela própria natureza secreta do problema e pelos critérios adotados no levantamento de dados" (Graça, 1971, p. 65). Para além da dimensão secreta à época, a falta de dados da toxicomania comunista se explica talvez por ter sido um problema mais imaginado do que experimentado. A documentação não comprova a ligação efetiva entre subversão comunista e drogas.

A maconha era a droga mais consumida devido ao seu "preço mais acessível, a sua natureza sólida e a forma de utilização através de cigarros, de fácil porte, manuseio e transporte" (Ministério do Exército, 1981, p. 3). A agência do SNI em Porto Alegre registrou o "descenso gradual dos princípios morais, [apontando que] o tráfico e o uso de drogas (principalmente a maconha) estão se acentuando" (Serviço Nacional de Informações, 1980b, p. 17). Em 1980, os dados sobre a "pesquisa realizada no período de 1977 a 1979 pelo instituto de Medicina Social e de Criminologia concluiu que cerca de $10 \%$ da população estudantil de São Paulo são usuários experimentadores de drogas ou tóxicos" (Serviço Nacional de Informações, 1980a, p. 2). A droga era "disseminada nas escolas, universidades e outros centros de reunião de jovens, principais alvos da obstinada e criminosa ação dos traficantes [...] como os que se servem da ilegal atividade para alcançar fins subversivos" (Ministério do Exército, 1981, p. 3).

O moralismo neste período salientou que, "se seus filhos, fundamentalmente os de classe média e média alta, estão se tornando 'subversivos' ou 'drogados', algo está errado" (Coimbra, 1997, p. 426). Para frações de militares, a crise da família e sua desestruturação geravam jovens desviantes. Militares e profissionais de psicologia buscaram pesquisar as causas desse "desvio". Uma investigação feita em 1969, com 260 presos políticos, indicou que uma das causas do encarceramento era o "descaso dos pais pelos problemas da mocidade" (Coimbra, 1997, p. 431). Outro inquérito concluiu que "é no lar que se encontra a melhor trincheira contra os desvios da moral e da conduta social" (Coimbra, 1997, p. 433). Especialistas no campo da saúde opinaram sobre a problemática das drogas à época. Além de sublinharem os problemas de saúde física e emocional, acrescentavam a "agonia de uma civilização" provocada pela revolução tecnológica que desumanizou e massificou os jovens segundo os ditames da indústria cultural. Garcia (1972, p. 159) concluía existir "relação direta entre progresso tecnológico e desenvolvimento da agressividade huma- 
na" e percebia um déficit de valores religiosos e elos familiares - que gerava a “orfandade existencial dos jovens" (Garcia, 1972, p. 163).

Alguns textos moldaram a percepção dos órgãos repressivos. Em 01 de setembro de 1972, o psiquiatra A. C. Pacheco e Silva apresentou uma Conferência na Associação Médica Brasileira. Intitulado "As toxicomanias e a segurança nacional”, o texto foi difundido pelo Centro de Informações da Aeronáutica (CISA) para cerca de 130 agências do Estado sob o argumento de que o assunto era "de real interesse das Forças Armadas" e devia "ser de conhecimento de todos os militares". Para o psiquiatra, "as nações livres [...] [estavam] constantemente ameaçadas [...] por elementos interessados em nelas implantar o regime comunista". Lançavam "todos os meios e recursos [...] para destruir a resistência física, mental e moral daqueles que se insurgem. Os tóxicos são hoje largamente empregados com essa finalidade, revelando-se um recurso poderoso". Pacheco e Silva afirmou que essa estratégia era defendida por Mao Tsé Tung e que estava comprovado por "pesquisas realizadas por entidades internacionais, que Pequim utiliza o tráfico de drogas como recurso" (Ministério da Aeronáutica, 1973, p. 4).

Amigo do Marechal Castelo Branco e próximo aos círculos de poder durante a ditadura (Cowan, 2012), Pacheco e Silva sublinhava que os tóxicos geravam "efeitos deletérios": mal-estar; antagonismos, insegurança moral e degradação dos costumes. Pessoas desiludidas e revoltadas eram vulneráveis ao inimigo que as tornava viciadas e escravizadas. Executavam atos criminosos a mando dos dirigentes, perdiam o senso moral, a ética e desprezavam a família. A droga modificava a personalidade dos viciados, a exemplo dos jovens, "que viviam em lares abastados e bem formados, sem demonstrar qualquer tendência para a criminalidade, [...] [e passavam a agir] como terríveis delinqüentes anti-sociais". Pacheco defendia medidas enérgicas contra a toxicomania, pois "a Segurança Nacional [...] [exigia] [...] a formação de uma consciência ideológica, política, social, sanitária e moral” (Ministério da Aeronáutica, 1973, p. 10).

O segundo texto que embasou a toxicomania como estratégia comunista foi assinado pelo antimarxista Bernard Hutton - pseudônimo do ex-embaixador Tcheco Joseph Heissler, que pediu asilo político em Londres após a entrada da Tchecoslováquia no Bloco Soviético (Lima, 2017, p. 117). Publicado em 1972, "Os Subversivos" afirmava que, "entre 1965 e 1967, os chefes subversivos de Mao Tsé Tung e suas redes" enviaram "uma instrução em código para todos os seus agentes [...]. A ordem era "aproveitar todas as oportunidades para intensificar o vício de drogas” (Hutton, 1975, p. 173). Para Hutton, “as drogas enfraquecem a 
força de vontade e destroem a capacidade para os julgamentos morais. Os viciados são escravos de um desejo". Para o autor, “os fornecedores não se preocupam muito com os lucros. [...] O objetivo é destruir a estrutura moral das democracias do Ocidente" e "quem inventou as drogas para o mundo capitalista foram os chineses, mas os russos logo os acompanharam [...] se concentrando na corrupção das crianças da escola e nos jovens" (Hutton, 1975, p. 179).

Em 31 de maio de 1973, o MEC/DSI circulou materiais sobre o risco comunista, recomendando o livro de Hutton, que poderia ser adquirido "em qualquer livraria [...] para maior esclarecimento da matéria" (Ministério da Educação e Cultura..., 1973, p. 2). Um destes materiais, "Como eles agem" denuncia que os comunistas usavam o sexo ilimitado e as drogas para a doutrinação comunista. O MEC compreendia que "o degradante processo que incentiva a juventude ao uso dos tóxicos tem como objetivo corromper a mente dos jovens e torná-los dependentes dos traficantes, contribuindo assim para os cofres do comunismo internacional de acordo com a Resolução aprovada na Conferência Tricontinental de Havana" (Ministério da Educação e Cultura, s.d., p. 5).

Estas três referências que modelaram o argumento da toxicomania comunista foram difundidas pelas comunidades de informações no início dos anos 1970 - contexto já mencionado de engajamento da repressão no combate à resistência armada ao regime e a novos sujeitos contestatórios. A suposta resolução da Tricontinental de Havana não é comprovada; não há nenhum trecho transcrito, nem fonte que ampare esta informação. Isso alimenta a hipótese de instrumentalização anticomunista de um evento que realmente aconteceu - a Conferência - interpretado sob a lógica conspirativa. Hutton foi uma referência largamente utilizada nos documentos para conferir autoridade ao argumento repetido à exaustão. A menção a Pequim e a Moscou se alinha ao anticomunismo hostil voltado às Revoluções Chinesa e Russa, amplificado pela Guerra Fria e pelo papel dos EUA, que conectou o tráfico de drogas à China e à União Soviética. Um dos argumentos comuns a estas representações foi discutido por Lima (2017). Para o autor, a suposta deliberação da Conferência Tricontinental de Havana é uma falsa resolução citada para "conferir veracidade ao que se identifica a uma teoria da conspiração" (Lima, 2017, p. 116). Convém reproduzir as críticas a Hutton e ao relatório. Elas podem ser ampliadas para se analisar este argumento da toxicomania comunista:

supondo que o autor teve contato com documentos secretos verdadeiros e importantes que revelam um problema real encoberto, e que procura divulgá-los de 
maneira persuasiva e convincente ao público. Por que o autor não reproduziu nenhuma imagem ou fotografia desses documentos no livro? Por que preferiu transcrevê-los, sem nenhuma imagem exemplo? Lembrando que o livro reproduz algumas imagens e fotografias, esses documentos secretos não teriam prioridade em ser reproduzidos no livro? É com esse tipo de referência bibliográfica e dinâmica de falsificações que o DSI/MEC elaborava seus materiais. Falsificações grosseiras e teorias de conspiração comunista mundial (Lima, 2017, p. 119).

O medo da subversão devido ao uso das drogas foi alimentado também por informações sobre o elevado consumo nos EUA. De acordo com Carvalho (1996, p. 29-30), "a dimensão do problema [nos EUA] estava se agravando, [...] onde o consumo de droga, ainda identificado com os movimentos contestatórios, gerava clima de total transgressão do status quo. Nixon e Bush, este último representante dos EUA em relação à política de drogas na ONU, conduzem a opinião pública a elegerem as drogas, principalmente a heroína, como o inimigo interno da nação [...][,] [começando a surgir a discussão sobre a possibilidade de existência de novo inimigo dos EUA: o inimigo externo". Para a criminóloga Del Olmo, "não era conveniente naquele momento da guerra do Vietnã atacar os principais centros de produção [...]. Seus integrantes, junto com uma série de governantes da região, eram grandes colaboradores da CIA na guerra e esta, por sua vez, apoiava o tráfico de ópio por razões de segurança". Além disso, "tampouco se podia atacar o crime organizado, a farsa da Máfia, encarregada na época do tráfico de heroína, por suas vinculações com altos funcionários do governo. Era mais adequado responsabilizar pelo problema a China de Mao, com o que também se compraziam os governos inimigos da China". Para a autora, a criação do inimigo externo - o tráfico - "era a forma de responsabilizar pelo consumo de drogas no 'Mundo Livre' um país então inimigo; discurso que se difundira em outros países na mesma época com grande intensidade" (Del Olmo, 1990, p. 41). Um livro publicado em 1972 já sublinhava que, "desde a fundação da República Popular da China, em 1949, porta-vozes oficiais e não-oficiais dos Estados Unidos e Taiwan têm acusado repetidamente que os comunistas chineses estavam exportando quantidades de heroína" (Mccoy; Read; Adams II, 1972, p. 145). De acordo com Behr (1981 apud Del Olmo, 1990, p. 41), “a Guerra do Vietnã foi, se não a madrinha, pelo menos a testemunha do casamento da heroína com a política. A teoria de que a China estava envenenando o mundo livre com a heroína recebeu nos círculos do Serviço Secreto um nome peculiar, 'O Pacto de Pequim', que imediatamente foi adotado também pelos jornalistas”. 
Carvalho (1996) afirma que essa política dos EUA se caracterizou pela demonização da droga e pelo maniqueísmo da luta do bem contra o mal. A tipologia moral foi se confundindo com outros estereótipos, sobretudo a ideia de agentes corruptores dos jovens. Esse aspecto foi chave para a construção do estereótipo do criminoso como um perigo para a sociedade, junto a outras categorias como a dependência e a criação do traficante no discurso jurídico. Rolim e Barros (2014, p. 177-178) sublinham que o "aparato repressivo-judicial" não ficou indiferente ao contexto: operadores jurídicos brasileiros leram os protestos juvenis pela chave do perigo, da ilegitimidade e da desordem.

A política proibicionista foi construída na América Latina com eventos para unificar as ações no continente, mudanças na legislação dos países, políticas específicas, criação de comitês locais e Conselhos. As Embaixadas dos EUA organizaram campanhas antidrogas na região. Essa política dos EUA de combate às drogas ilícitas teve algum efeito no Brasil. Afinal, a DSN teve influxos dos EUA, influenciou a ditadura e esteve marcada pela guerra ao inimigo interno. O golpe de 1964 "criou as condições para a implantação do modelo bélico" de combate às drogas (Batista, 1997, p. 84). Castello Branco promulgou a Convenção Única sobre Entorpecentes, fazendo o país ingressar na rede transnacional de combate às drogas (Carvalho, 1996). O governo brasileiro apoiou a política proibicionista, a exemplo da Lei 4483/1964, que reorganizava o Departamento Federal de Segurança Pública, criando o Serviço de Repressão a Tóxicos e Entorpecentes (Carvalho, 2012). Em 1967, editou o Decreto Lei 159. Dias depois do AI-5, o Decreto Lei 385 foi baixado, estabelecendo "a mesma sanção para traficante e usuário" (Carvalho, 1996, p. 26). Brandão (2018, p. 4) ressalta que Médici "foi o que mais ostensivamente se utilizou do discurso da 'guerra às drogas' para fins de promoção política”. A Lei 5.726/71 alterou o Código Penal Brasileiro, atualizando a criminalização da "posse e guarda de substância que determina dependência física e psíquica", alinhando-se à política de "tolerância zero" levada a cabo nos EUA pelo presidente Nixon no mesmo período" (Brandão, 2018, p. 8). A propósito, motivado pela apreensão de LSD em 1971, algo raro à época, um agente do FBI esteve no Brasil para "acompanhar o inquérito relativo ao tráfico de entorpecentes", pois o LSD estaria "sendo traficado na rota Miami-Buenos Aires-Rio de Janeiro" (Delmanto, 2018, p. 196). Esse é um dado para mapear a relação entre o governo dos EUA e a ditadura no Brasil, no que diz respeito à política em relação às drogas.

A Lei 5.726/71 aumentou as penas e também impôs que os diretores de escolas informassem às autoridades sanitárias casos de uso e tráfico de drogas, 
sob o risco de perderem o cargo (Batista, 1997, p. 86), bem como enquadrou estrangeiros envolvidos com o uso e o tráfico, imputando-lhes acusações de crimes contra a segurança nacional. Já a Lei 6.368/76 "marca uma inflexão importante na política criminal sobre drogas [...] [e] possui um viés abertamente bélico, reproduzindo quase ipsis literis o discurso da war on drugs estadunidense" (Brandão, 2019, p. 106). Nilo Batista (1997, p. 87) considera que "a produção jurídico-penal daquela conjuntura absorveu a ideia de que a generalização do contato de jovens com drogas devia ser compreendida no quadro da guerra fria, como uma estratégia do bloco comunista para solapar as bases morais da civilização cristã ocidental, e que o enfrentamento da questão devia valer-se de métodos e dispositivos militares".

A problemática dos "tóxicos e entorpecentes" foi conectada ao "terrorismo". Ambas as questões eram formuladas em termos bélicos. Para Brandão (2018, p. 10), "apesar de a ditadura não ter sido o primeiro regime a operar medidas proibicionistas, foi certamente o primeiro a se dedicar declaradamente ao que conhecemos ainda hoje como 'Guerra às Drogas'. Constrói-se assim, por meio das campanhas de lei e ordem e da reelaboração do significado de 'Segurança Nacional', o estereótipo político-criminal de um novo inimigo interno: o traficante". Vera Batista (2003, p. 40) argumenta que, "na transição da ditadura para a 'abertura democrática' (1978-1988), houve uma transferência do terrorista para o traficante. [...] O inimigo, antes circunscrito a um pequeno grupo, se multiplicou nos bairros pobres, na figura do jovem traficante”. A autora assinala o aumento do tráfico e do consumo de cocaína a partir dos anos 1970, sublinhando que "aos jovens de classe média, que a consomem, aplica-se o estereótipo médico, e aos jovens pobres, que a comercializam, o estereótipo criminal. No início dos anos setenta aparecem as primeiras campanhas de 'lei e ordem' tratando a droga como inimigo interno. Permitia-se assim a formação de um discurso político para que a droga fosse transformada em uma ameaça à ordem" (Batista, 2003, p. 84).

Essa ameaça engajou Zonildo Castello Branco. Crítico da transição proposta por Geisel, o Delegado editou um dicionário contrassubversivo. Em 1977 - ano da publicação do dicionário -, frentes políticas se reorganizaram contra a ditadura, especialmente o movimento estudantil. Zonildo Castelo Branco alertou "que os subversivos ainda representavam uma ameaça ao país, discordando, portanto, da distensão e justificando a necessidade da continuidade do seu trabalho, das ações repressivas" (Hessmann, 2011, p. 123). O Delegado afirma que os subversivos "costumam usar tóxicos nos momentos que antecedem suas prisões, ou logo após de presos, com o fim de não apresentarem 
condições para o interrogatório", sustentando que os comunistas vendiam a baixo custo ou distribuíam tóxicos para conquistar pessoas pelo vício: “o livro 'Os subversivos', de J. Bernard Hutton [...] aborda muito bem essa matéria” (Hessmann, 2011, p. 98).

O delegado conectava droga a subversão no "Rio de Janeiro, capital por excelência da liberalização dos costumes, das mobilizações políticas e sociais e o centro artístico e cultural do país" (Hessmann, 2011, p. 59). O "dicionário da subversão" e os documentos já mencionados embasaram o cânone da toxicomania comunista durante a "abertura política" - um período marcado por tensões, especialmente entre o projeto da distensão dirigido por Geisel e a resistência da linha-dura. Essa recusa implicou reações hostis, como o assassinato de opositores, a explosão de bombas e outros atentados durante o Governo Figueiredo (1979-1983), para se desestabilizar a transição. A distensão veio acompanhada da profusão de representações anticomunistas pelas forças de segurança, apontando a decadência da nova ordem política e moral, bem como sublinhando a vulnerabilidade juvenil à ação comunista.

Um dos militares de alto escalão que alimentou este repertório foi o General Ferdinando de Carvalho. Em 1977, lançou "Os Sete matizes do vermelho", afirmando que "o subversivo, como o viciado e o criminoso, se envolve em uma rede emaranhada de compromissos, da qual dificilmente se pode desprender" (Carvalho, 1977, p. 30). Noutra passagem, indica os recursos usados pelos comunistas para influenciar os jovens, ressaltando "os tóxicos, que aniquilam a vontade e induzem o vício incontrolável” (Carvalho, 1977, p. 88). Como bem salientou Sandra Souza, "Carvalho com sua ficção buscava 'educar', 'aconselhar', defender o povo brasileiro dos ataques à 'moral e aos bons costumes”' (Souza, 2017, p. 414). Além disso, a Editora da Biblioteca do Exército considerou o livro como uma "forma inteligente de combate [...] que a conjuntura o exige, sem rebuços" (Carvalho, 1977, p. 7).

Além de lideranças institucionais, diversos órgãos de informações e segurança conectaram subversão, drogas e promiscuidade. Em 1978, o Serviço de Espionagem rastreou um show ocorrido numa Faculdade em Santos, recheado de "pornografia", "política" e "promiscuidade", com a apresentação de estudantes "seminus [...][,] [com] cenas de sexo [...] [com] pederastas, em bailados e danças tipo discotéque com a parte traseira do corpo completamente nua [...]. Nos cantos mais isolados rapazes e moças faziam uso de maconha" (Ministério da Aeronáutica, 1978, p. 1). A residência estudantil da UFBA também esteve na mira da vigilância. Em 1980, um pedido de busca foi despachado contra um grupo que pregava a "liberdade total [...] [inclusive] práticas sexuais, 
homossexuais, consumos de tóxicos, ausência de roupas (andar nus), e outras taras, próprias de locais onde não se respeita a condição humana e onde falta autoridade para manter os princípios morais" (Serviço Nacional de Informações..., 1980c, p. 2). Em 1981, o 1 Exército circulou "Tóxico e corrupção como instrumento da subversão". O documento veiculou a categoria de "traficante ideológico", que teria se unido ao traficante mercenário "na tarefa criminosa de corromper a juventude e subverter a ordem interna". Para fundamentar a assertiva, cita um dirigente do Partido Comunista da União Soviética, que defendia a estratégia de: "1) disseminar o tóxico em meio à juventude, principalmente, nas escolas e universidades; 2) desmoralizar as autoridades constituídas aproveitando-se de suas fraquezas morais; 3) destruir a família, através da pornografia, da pornochanchada, usando-se os meios de publicidade bem como os teatros e cinemas (Ministério do Exército, 1981, p. 6-7).

Algumas destas preocupações emergiram com mais força naquele contexto, com o florescimento da "indústria cultural", acompanhadas de críticas anticomunistas e conservadoras. Além de filmes com cenas pornográficas, as pornochanchadas "despontavam como um mercado bastante lucrativo, com a exploração de cenas de nudez e de relações sexuais", "o mercado editorial [...] [consolidava] uma produção de livros em maior escala", com "influência da literatura internacional abordando temas como violência e sexo", "novas discussões e comportamentos [emergiam nas] [...] novelas, minisséries e programas de auditório [...] [chocando] a suscetibilidade de muitas pessoas moralmente mais conservadoras" (Marcelino, 2011, p. 25).

Atento aos novos perigos, o Centro de Informações da Polícia Federal monitorou uma organização que promovia “a desagregação familiar". Instrumento de combate político, o relatório demarcava que, "particularmente quanto à subversão, que alguns 'liberais' e ingênuos dizem extinta", percebe-se "o solapamento progressivo de todos os valores morais e espirituais", de modo que não se seja "mais capaz de oferecer resistência à investida comunista [...]. O fundamental [...] ainda é a família - e é precisamente nessa célula que os comunistas - exatamente como o câncer - estão atuando" (Ministério da Justiça, 1983, p. 2). Sontag (2007, p. 72) alertou que "o uso do câncer no discurso político estimula o fatalismo e justifica 'medidas severas' bem como reforça com veemência a noção de que a doença é necessariamente fatal”. Com base no catastrofismo e na patologização dos comunistas, o documento denunciava que os jovens entregavam-se "a orgias sexuais onde predomina o consumo de tóxicos [...] [inclusive] entre menores de idade” (Ministério da Justiça, 1983, p. 5). 
Estes anticomunistas identificavam uma Internacional Comunista organizando a juventude. Esta percepção veiculou uma visão onipotente e onipresente do movimento comunista, alimentada por essa fração preocupada com a autopreservação, especialmente durante a abertura política, pelo receio da desagregação e de futuras punições (Fico, 2001). Por isso, criou novos adversários, atualizou antigos inimigos e operou com estratégias de perseguição, incluindo o delírio e a paranoia (Samways, 2014; Faria, 2015). A acusação de comunista foi aplicada indistintamente sob o pressuposto de que era "alguém possuído por forças malignas e incontroláveis". O medo deste "outro" supostamente "detentor de um poder absoluto provoca, em seus extremos, atitudes que desfazem as fronteiras entre realidade e fantasia" (Brepohl de Magalhães, 1997, p. 7-8).

Influenciados pela teoria do complô assentada na suspeição generalizada, na convicção anterior à experiência, num tom apocalíptico, catastrófico e paranoico, os documentos anticomunistas explorados neste texto procuraram e construíram ameaças entre os comunistas. Para tanto, tiveram que, "a partir da mesma linguagem, realizar um processo de acomodação da realidade à mesma linguagem". Cada nova situação conjuntural esteve "submetida à necessidade imperiosa de subsumir-se à mesma linguagem, ao mesmo conjunto ortodoxo de conceitos e categorias" (Koselleck, 1992, p. 145).

As fontes indicam uma conexão entre as agências de alguns países da América Latina, numa época marcada por experiências de Terrorismo de Estado, guerrilhas e narcotráfico. Essa preocupação com subversão, família e moral esteve na agenda das ditaduras, o que exige uma abordagem transnacional (Brito, 2020). De acordo com Comblin (1978), “os discursos dos generais latino-americanos batem todos os recordes. A se acreditar neles, suas ditaduras não têm outra meta senão restaurar a moralidade da nação" (Comblin, 1978, p. 222-223). Essa moralidade reverberou na obsessão civil-militar anticomunista e conservadora com o comportamento juvenil nas Américas (Padrós, 2005; Pensado, 2014; Bohoslavsky, 2015; Sempol, 2015). Nos EUA, em maio de 1968, um memorando do FBI descreve que os ativistas da Nova Esquerda desconsideravam os "padrões morais e sociais geralmente aceitos", portavam "negligência na limpeza pessoal”, pois reproduziam "promiscuidade sexual" e “experimentavam drogas” (Davis, 1997, p. 47). No México, grupos civis de direita leram os anos 1960 como um período de crise política e decadência moral. Setores de uma organização de jovens conservadores realizaram campanhas anti-hippie, expandindo-as para "brigadas de limpeza", visando combater alunos supostamente envolvidos com uso e tráfico de drogas nos campi 
(Pensado, 2014, p. 499). Membros das forças armadas argentinas enfatizaram como os dois "males estrangeiros" - comunismo e drogas - se espalhavam entre os jovens (Manzano, 2015, p. 52). As autoridades firmaram um tratado bilateral de cooperação com os EUA que foi expandido em 1973. Em troca, os EUA ofereceriam financiamento e capacitação policial. Ainda de acordo com Valeria Manzano, as autoridades argentinas acolheram as ofertas, especialmente para controlar os supostos drogados, "interpretaram o problema das drogas como um assunto de segurança nacional e associaram os "toxicômanos" à figura do inimigo interno. Essencialmente anticomunistas, as ideologias de segurança nacional justificaram e orientaram projetos políticos repressivos" (Manzano, 2014a, p. 52). Na América Latina, a escalada repressiva foi acentuada nos anos 1980 sob justificativa de combater a nova ameaça à segurança que seria o narcoterrorismo - a associação entre guerrilhas de esquerda e tráfico de cocaína (Rodrigues, 2012, p. 18). Reagan acentuou a militarização da "guerra às drogas", mas isto é tema para outra pesquisa.

\section{CONSIDERAÇÕES FINAIS}

A Guerra Fria e os novos questionamentos à ordem em reação à "revolução dos costumes" dos anos 1960-1970 atualizaram o anticomunismo no Brasil na sua dimensão moral, com o argumento da toxicomania comunista. Além da subversão comunista, os acervos repressivos pesquisados demonstram que os fantasmas das drogas estiveram associados à promiscuidade sexual, se aproximando das matrizes do proibicionismo, o qual demonizava as drogas por sua conexão com a imoralidade e a destruição da família. Em muitos momentos, o tripé subversivo-drogado-promíscuo pautou a documentação. Portanto, foram categorias usadas para estigmatizar grupos minoritários - sob a acusação de serem comunistas - a partir de critérios políticos, ideológicos, comportamentais, estéticos, morais e sexuais.

O anticomunismo foi um extenso guarda-chuva. Diversas manifestações críticas à ditadura no Brasil - inclusive comportamentos e práticas contestatórios de frações juvenis, como a incursão nas drogas - foram estigmatizados como resultado da sua supostamente nefasta influência. Isso tem a ver com ignorância, mas também com uma obsessão paranoica em encontrar na realidade nexos com o combate ao inimigo interno. Além disso, não deve ser desprezada a instrumentalização do fantasma da conspiração comunista mundial para reforçar a coesão de segmentos anticomunistas, bem como para disputar poder no interior do regime. 
Típicas de um pensamento autoritário, as noções de ilegitimidade e de insanidade nos protestos anti-regime orientaram o anticomunismo. $\mathrm{O}$ estereótipo da droga como o mal e dos usuários como viciados que perdem a vontade e a capacidade de escolha foram importantes pressupostos. A visão conspirativa se reproduzia assentada na hiper-valorização dos comunistas. Esse outro existia a partir das preocupações dos anticomunistas. Por isso, esses documentos falam mais da obsessão anticomunista do que daqueles que eles visavam denunciar. Não havia preocupação em se conhecer efetivamente aqueles sujeitos plurais que desnaturalizavam a ordem. O mais eficiente parecia ser classificá-los e enquadrá-los como conspiração comunista - chave de leitura que pressupunha sujeitos onipotentes e onipresentes. Essa esquizofrenia ideológica visava promover o "espírito de corpo" em torno do inimigo interno.

Estas representações não devem ser generalizadas a todos os anticomunistas militares, tampouco aos que ocuparam postos estratégicos no regime. Convém investigar como diferentes esferas do governo e do Estado lidaram com elas. Possivelmente, existiam conflitos, nuances e tensões a respeito daqueles conteúdos. Alguns temas merecem pesquisa, a exemplo das redes de transmissão e circulação destes textos, incluindo sua difusão pela imprensa, TV e por agências oficiais de propaganda. A documentação explorada não é suficiente para concluir se as agências repressivas levavam a sério essa conspiração e em que medida o combate foi operacionalizado. Além das opiniões das forças repressivas estatais, é necessário investigar se houve a produção de registros da criminalidade real dos toxicômanos tidos como ameaças à segurança nacional. Tudo isso desembocará em interrogar se, além de um discurso radical veiculado por autoridades militares e civis, o regime ditatorial militar incorporou essas representações em torno da toxicomania comunista, bem como qual foi a reação por parte das Forças Armadas e dos órgãos de repressão aos tóxicos. Enquanto frações das comunidades de segurança e informação responsabilizaram o Movimento Comunista Internacional pela toxicomania, talvez os agentes policiais que lidavam com o combate ao tráfico funcionassem com outros paradigmas, especialmente identificando o inimigo interno não com base em critérios políticos e ideológicos, mas a partir de dimensões de raça e classe.

As representações da toxicomania comunista articulada com noções de moral, sexo e gênero circularam nas Américas e nutriram as ditaduras. Investigar o tema em escala transnacional pode ser fecundo para a historiografia. Acessar arquivos do Partido Comunista da União Soviética, do Partido Comunista Chinês e da Tricontinental Havana é necessário, bem como esquadri- 
nhar o papel da noção de guerra revolucionária - vertente francesa - na modelagem desse discurso. Torna-se relevante igualmente pensar as relações entre a ditadura no Brasil e as agências de Estado dos EUA na circulação dessa matriz anticomunista proibicionista. $\mathrm{O}$ caso argentino pode ser testado como hipótese para se pensar o Brasil: sem esquecer as ansiedades e os temores relacionados ao contexto, é pertinente analisar uma eventual instrumentalização deste medo por parte de frações de militares brasileiros interessados em estreitar relações com os EUA e, sob a fachada de guerra às drogas, almejar acordos bilaterais que possibilitassem investimento na estrutura material das forças de segurança.

Ainda não há evidência do argumento da toxicomania como estratégia comunista ter tido ampla audiência. Sem esquecermos que a ditadura brasileira não se apoiou em uma ampla mobilização social, essas representações entusiasmaram um pequeno segmento, ainda que articulado transnacionalmente em redes de extrema-direita civil e militar. Embora seja simplificador analisar estas representações e o imaginário anticomunista a partir unicamente da manipulação do real, seria ingenuidade perder-se de vista esta perspectiva. A crítica aos documentos principais que veicularam o argumento sem fundamentação e prova é importante para caracterizar o anticomunismo como visão de mundo que alimentou a ação de sujeitos a partir de teorias da conspiração, ansiedades e pânico em torno de questionamentos e mudanças comportamentais reais, mas que teve componentes de manipulação e instrumentalização. Relembrar essas noções é primordial, especialmente em tempos de fake news e atualização do anticomunismo moral que, por exemplo, deprecia a universidade como lugar de "suruba" e "distribuição de drogas", sem nenhuma evidência.

\section{REFERÊNCIAS}

ABREU, João Batista de. As manobras da informação: análise da cobertura jornalística da luta armada no Brasil, 1965-1979. Rio de Janeiro: Mauad; EDUFF, 2000. 272 p.

AUDOIN-ROUZEAU, Stéphane. Massacres. O corpo e a guerra. In: CORBIN, Alain; COURTINE, Jean-Jacques; VIGARELLO, Georges. História do Corpo: As mutações do Olhar: O Século XX. Petrópolis, Rio de Janeiro: Vozes, 2011. p. 365-416.

ALMEIDA, Maria Hermínia Brandão Tavares de; WEIS, Luiz. Carro-zero e pau-de-arara: o cotidiano da oposição de classe média ao regime militar. In: NOVAIS, Fernando Antonio; SCHWARCZ, Lilia Moritz. História da vida privada no Brasil: contrastes 
da intimidade contemporânea. Vol. 4. São Paulo: Companhia das Letras, 1998. p. 319-409.

ALVES, Iracélli da Cruz. Feminismo entre ondas: mulheres, PCB e política no Brasil. Tese (Doutorado em História). Universidade Federal Fluminense, Niterói, 2020.

BATISTA, Nilo. Política criminal com derramamento de sangue. Revista Brasileira de Ciências Criminais, São Paulo: Revista dos Tribunais, v. 5, n. 20, 1997, p. 77-94.

BATISTA, Vera Malaguti. Difíceis Ganhos Fáceis: drogas e juventude pobre no Rio de Janeiro. Rio de Janeiro: Revan, 2003.

BECKER, Howard S. Outsiders: estudos de sociologia do desvio. Rio de Janeiro: Zahar, 2008.

BEHR, Hans-Georg. La droga, potencia mundial: el negocio com el vicio. Barcelona: Ed. Planeta, 1981.

BOHOSLAVSKY, Ernesto. It's only rock and roll, but I (dis)like it. Anticomunismo, conservadurismo moral y persecución al primer rock argentino en la década de 1960. In: FIUZA, Alexandre et al. (Coords). Anais do II Congresso Internacional de Estudos do Rock. Cascavel: UNIOESTE, 2015.

BRAGHINI, Katya Mitsuko Zuquim. Juventude e pensamento conservador no Brasil. São Paulo: EDUC, 2015.

BRANDÃO, Luiz Henrique Santos. Do subversivo ao traficante: o papel da guerra às drogas na construção do inimigo interno no Brasil. In: PEREIRA, Denise (Org.). A transversalidade da prática do profissional de história. Ponta Grossa, PR: Atena Editora, 2019. p. 105-119.

BRANDÃO, Luiz Henrique Santos. Do subversivo ao traficante: uma arqueologia do conceito de "tóxico-subversão". In: III SEMINÁRIO NACIONAL DE HISTÓRIA E CONTEMPORANEIDADES: Brasil: autoritarismo, cultura política e direitos humanos, 3, 2018, Universidade Regional do Cariri. Anais do Seminário Nacional de História e Contemporaneidades. Crato, 2018. p. 1-11.

BREPOHL DE MAGALHÃES, Marionilde D. A lógica da suspeição: sobre os aparelhos repressivos à época da ditadura militar no Brasil. Revista Brasileira de História, v. 17, n. 34, 1997, p. 203-220.

BRITO, Antonio Mauricio Freitas. "Um verdadeiro bacanal, uma coisa estúpida": anticomunismo, sexualidade e juventude no tempo da ditadura. Anos 90, Porto Alegre, v. 26, 2019, p. 1-22.

BRITO, Antonio Mauricio Freitas. A subversão pelo sexo: representações anticomunistas durante a ditadura no Brasil. Varia Historia, Belo Horizonte, vol. 36, n. 72, p. 859-888, 2020.

CARNEIRO, Henrique. Drogas: a história do proibicionismo. São Paulo: Autonomia Literária, 2018.

CARVALHO, Ferdinando de. Os sete matizes do vermelho. Rio de Janeiro: Biblioteca do Exército Editora, 1977. 
CARVALHO, Jonatas C. de. A América Latina e a criminalização das drogas entre 19601970: prenúncios de outra guerra por outra América. In: XV ENCONTRO REGIONAL DE HISTÓRIA DA ANPUH-RIO, 2012, São Gonçalo. Anais do XV Encontro Regional de História da ANPUH-Rio, 2012. p. 1-21.

CARVALHO, Salo de. A política criminal de drogas no Brasil: do discurso oficial às razões da descriminalização. Rio de Janeiro: Luam, 1996.

CHIRIO, Maud. A politica nos quartéis: revoltas e protestos de oficiais na ditadura militar brasileira. Rio de Janeiro: Zahar, 2012.

COIMBRA, Cecilia Maria B. Algumas práticas "psi” no Brasil do "milagre". In: FREIRE, Alípio; ALMADA, Izaías; PONCE, J. A. de Granville (Orgs.). Tiradentes, um presídio da ditadura: memórias de presos políticos. São Paulo: Scipione, 1997. p. 423-438.

COIMBRA, Cecilia. Guardiães da ordem: uma viagem pelas práticas psi no Brasil do "Milagre". Rio de Janeiro: Oficina do Autor, 1995.

COMBLIN, Padre Joseph. A Ideologia da Segurança Nacional. Rio de Janeiro: Civilização Brasileira, 1978.

COWAN, Benjamin A. Securing Sex: morality and repression in the making of Cold War Brazil. Chapell Hill: The University of North Carolina Press, 2016.

COWAN, Benjamin A. "Why Hasn't This Teacher Been Shot?" Moral-Sexual Panic, the Repressive Right, and Brazil's National Security State. Hispanic American Historical Review, Durham, v. 92, n. 3, p. 403-436, 2012.

D'ARAUJO, Maria Celina; SOARES, Gláucio Ary Dillon; CASTRO, Celso (Introd. e Org.). Os anos de chumbo: a memória militar sobre a repressão. Rio de Janeiro: Relume-Dumará, 1994.

DAVIS, James Kirkpatrick. Assault on the Left: the FBI and the sixties Antiwar Movement. Westport, Connecticut, London: Praeger, 1997.

DELMANTO, Júlio. Camaradas caretas: Drogas e esquerda no Brasil. São Paulo: Alameda Editorial, 2015.

DELMANTO, Júlio. História social do LSD no Brasil: os primeiros usos medicinais e o começo da repressão. Tese (Doutorado em História Social) - Faculdade de Filosofia, Letras e Ciências Humanas, Universidade de São Paulo, São Paulo, 2018. 295 p.

DEL OLMO, Rosa. A face oculta da droga. Rio de Janeiro: Editora Revan, 1990.

DUARTE, Ana Rita Fonteles. Homens e mulheres contra o inimigo: a mobilização do gênero pela ditadura militar brasileira (1964-1985). ANPUH, 26, 2011, São Paulo. In: Anais do XXVI Simpósio Nacional de História, São Paulo, 2011. p. 1-14.

DUARTE, Ana Rita Fonteles. Meios de comunicação, segurança nacional e a defesa da "moral e bons costumes": uma análise dos escritos da Escola Superior de Guerra (1964-1985). Embornal - Revista Eletrônica da Associação Nacional de História, Fortaleza, v. 6, n. 13, p. 7-21, 2016.

DUNN, Christopher. Desbunde and its Discontents: Counterculture and Authoritarian Modernization in Brazil, 1968-1974. The Americas, v. 70, n. 3, 2014, p. 429-458. 
FARGE, Arlette. O sabor do arquivo. Tradução de Fátima Murad. São Paulo: Edusp, 2009. FARIA, Daniel. Sob o signo da suspeita: As loucuras do poder ditatorial. Antíteses, Londrina, v. 8, n. 15, p. 221-240, 2015.

FICO, Carlos. "Prezada Censura”: cartas ao regime militar. Topoi - Revista de História, Rio de Janeiro, v. 5, p. 251-286, 2002.

FICO, Carlos. Como eles agiam. Os subterrâneos da Ditadura Militar: espionagem e polícia política. Rio de Janeiro: Record, 2001.

GARCIA, J. Alves. Poluição das drogas. Rio de Janeiro: Editora Rio, 1972.

GASPAROTTO, Alessandra. "O terror renegado": uma reflexão sobre os episódios de retratação pública protagonizados por integrantes de organizações de combate à ditadura civil-militar no Brasil (1970-1975). Dissertação (Mestrado em História) - Instituto de Filosofia e Ciências Humanas, Universidade Federal do Rio Grande do Sul, Porto Alegre, 2008.

GIRARDET, Raoul. Mitos e mitologias políticas. São Paulo: Companhia das Letras, 1987.

GOFFMAN, Erving. Estigma: notas sobre a manipulação da identidade deteriorada. Rio de Janeiro: Zahar Editores, 1975.

GRAÇA, Jaime Ribeiro da. Tóxicos. Rio de Janeiro: Editora Renes, 1971.

HESSMANN, Dayane Rúbila Lobo. Cartilha da repressão: Os ensinamentos de um delegado sobre a Subversão e a Segurança Nacional (1974-1977). Dissertação (Mestrado em História) - Setor de Ciências Humanas, Letras e Artes, Universidade Federal do Paraná, 2011. 142p.

HUTTON, J. Bernard. Os Subversivos. Rio de Janeiro: Biblioteca do Exército, Artenova, 1975.

JOFFILY, Mariana. No centro da engrenagem. Os interrogatórios na Operação Bandeirante e no DOI de São Paulo (1969-1975). Rio de Janeiro: Arquivo Nacional; São Paulo: Edusp, 2013.

JORNAL DO BRASIL. Jornal do Brasil, 19 e 20 jul. 1970, p. 5.

KAMINSKI, Leon Frederico. "O movimento hippie nasceu em Moscou”: imaginário anticomunista, contracultura e repressão no Brasil dos anos 1970. Antíteses, v. 9, n. 18, p. 467-493, 2017.

KLIMKE, Martin \& NOLAN, Mary. The globalization of the sixties. In: CHEN, Jian; KLIMKE, Martin; KIRASIROVA, Masha; NOLAN, Mary; YOUNG, Marilyn; WALEY-COHEN, Joanna. The Routledge handbook of the global sixties: between protest and nation-building. Abingdon, Oxon; New York: Routledge, 2018. p. 1-9.

KNIGHT, Peter. Making Sense of Conspiracy Theories. In: KNIGHT, Peter (Org). Conspiracy Theories in American History: an Encyclopedia. Santa Barbara, Calif: ABC-CLIO, 2003. p. 15-25.

KOSELLECK, Reinhart. Uma História dos Conceitos: problemas teóricos e práticos. Estudos Históricos. Rio de Janeiro, vol. 5, n. 10, p. 134-146, 1992. 
KÖSSLING, Karin Sant'Anna. As lutas anti-racistas de afro-descendentes sob vigilância do DEOPS/SP (1964-1983). Dissertação (Mestrado em História Social) - Faculdade de Filosofia, Letras e Ciências Humanas, Universidade de São Paulo, São Paulo, 2007. LAGÔA, Ana. SNI: Como nasceu, como funciona. São Paulo: Brasiliense, 1983.

LANGLAND, Victoria. Birth control pills and molotov cocktails: Reading Sex and Revolution in 1968 Brazil. In: JOSEPH, Gilbert; SPENSER, Daniela. From the Cold: Latin America's new encounter with the Cold War. Durham, NC: Duke University Press, 2008. p. 308-349.

LANGLAND, Victoria. Transnational connections of the global sixties as seen by a historian of Brazil. In: CHEN, Jian; KLIMKE, Martin; KIRASIROVA, Masha; NOLAN, Mary; YOUNG, Marilyn; WALEY-COHEN, Joanna. The Routledge handbook of the global sixties: between protest and nation-building. Abingdon, Oxon; New York, NY: Routledge, 2018. p. 15-26.

LIMA, Alexandre Siqueira. Primavera nos dentes: desbunde, anticomunismo e repressão na cidade em quadrinhos (1972-1973). Dissertação (Mestrado em História) - Instituto de Ciências Humanas, Universidade de Brasília, Brasília, 2017. 197 p.

MANZANO, Valeria. The Creation of a Social Problem: Youth Culture, Drugs, and Politics in Cold War Argentina. Hispanic American Historical Review, Durham: Duke University Press, v. 95, n. 1, p. 37-69, 2015.

MANZANO, Valeria. Política, cultura y el "problema de las drogas" en la Argentina, 1960-1980s. Apuntes de investigación del CECYP. Buenos Aires, año XVII, n. 24, p. 51-78, 2014a.

MANZANO, Valeria. The Age of Youth in Argentina: Culture, Politics, and Sexuality from Perón to Videla. Chapel Hill: University of North Carolina Press, 2014b.

MARCELINO, Douglas Attila. Subversivos e pornográficos: censura de livros e diversões públicas nos anos 1970. Rio de Janeiro: Ministério da Justiça, Arquivo Nacional, 2011.

MCCOY, Alfred W; READ, Cathleen B; ADAMS II, Leonard Palmer. The politics of heroin in Southeast Asia. New York: Harper Colophon Books, 1972.

MINISTÉRIO DA AERONÁUTICA. As Toxicomanias e a Segurança Nacional. CISA, p. 1 a 10 (Arquivo Nacional, Distrito Federal). 20/09/1973.

MINISTÉRIO DA AERONÁUTICA. II Show. VAZ 56.74, p. 1 (Arquivo Nacional, Distrito Federal). 14/12/1978.

MINISTÉRIO DA EDUCAÇÃO E CULTURA. Como eles agem, p. 1 a 24 (Arquivo Nacional, Rio de Janeiro), s.d.

MINISTÉRIO DA EDUCAÇÃO E CULTURA. Levantamento sobre Movimento Estudantil, 81 p., p. 1 a 11 (Arquivo Nacional, Distrito Federal). 31/05/1973.

MINISTÉRIO DA JUSTIÇA. Movimento Comunista Internacional "MCI" Tóxicos e subversão, p. 1 a 8 (Arquivo Nacional, Distrito Federal). 25/01/1973.

MINISTÉRIO DA JUSTIÇA. Alicerce da Juventude Socialista (AJS) promove a desagregação familiar, p. 1 a 10. (Arquivo Nacional, Distrito Federal). 01/09/1983. 
MINISTÉRIO DO EXÉRCITO. Infiltração subversiva no meio universitário em Brasília. ROS 33, p. 1 a 31 (Arquivo Nacional, Distrito Federal). 10/09/1973.

MINISTÉRIO DO EXÉRCITO. Histórico do uso do tóxico no Brasil, sua origem e meios legais para seu combate, p. 1 a 14. (Arquivo Nacional, Distrito Federal). 20/04/1981. MOTTA, Rodrigo Patto Sá. Em guarda contra o perigo vermelho: o anticomunismo no Brasil (1917-1964). São Paulo: Perspectiva, 2002.

MULLER, Angélica. Não se nasce viril, torna-se: juventude e virilidade "nos anos 1968". In: PRIORE, Mary del; AMANTINO, Marcia (Orgs.). História dos Homens no Brasil. São Paulo: Editora Unesp, 2013. p. 299-333.

PADRÓS, Enrique Serra. Como el Uruguay no hay...: terror de Estado e Segurança nacional, Uruguai (1968-1985): do Pachecato à ditadura civil militar. Tese (Doutorado em História) - Universidade Federal do Rio Grande do Sul, Porto Alegre, 2005. 433 p.

PENSADO, Jaime. "To Assault with the Truth": The Revitalization of Conservative Militancy in Mexico During the Global Sixties. The Americas, Cambridge: Cambridge University Press, v. 70, n. 3, p. 489-521, 2014.

PINSKY, Carla Bassanezi. Mulheres dos anos dourados. São Paulo: Contexto, 2014.

RAGO, Margareth. O Prazer no Casamento. Cadernos CERU, São Paulo, v. 7, série 2, p. 96-111, 1996.

RISÉRIO, Antônio. Duas ou três coisas sobre a contracultura no Brasil. In: COELHO, Claudio Novaes Pinto. Anos 70: trajetórias. São Paulo: Iluminuras; Itaú Cultural. 2005. RODEGHERO, Carla Simone. Religião e patriotismo: o anticomunismo católico nos Estados Unidos e no Brasil nos anos da Guerra Fria. Tese (Doutorado em História) Instituto de Filosofia e Ciências Humanas, Universidade Federal do Rio Grande do Sul, Porto Alegre, 2002.

RODRIGUES, Thiago. Narcotráfico e militarização nas Américas: vício de Guerra. Contexto Internacional, Rio de Janeiro, vol. 34, n. 1, p. 9-41, 2012.

ROLIM, Rivail Carvalho; BARROS, Patrícia Marcondes de. Drogas e juventude diante do aparato repressivo-judicial no período militar. Passagens. Revista internacional de história política e cultura jurídica, Rio de Janeiro, vol. 6, n. 1, p. 171-192, 2014.

ROLLING STONE. Rolling Stone, 18 abr. 1972, p. 13.

RUBIN, Gayle. Pensando o sexo: notas para uma teoria radical das políticas da sexualidade. 2012. Disponível em: https://repositorio.ufsc.br/bitstream/handle/123456789/1229/rubin_pensando_o_sexo.pdf. Acesso em: 29 out. 2020.

SALGADO, Plínio. Discursos: $1^{\text {a }}$ série 1946/1947. São Paulo: Panorama, 1949.

SAMWAYS, Daniel Trevisan. Inimigos imaginários, sentimentos reais: medo e paranóia no discurso anticomunista do Serviço Nacional de Informações (1970-1973). Tese (Doutorado em História) - Setor de Ciências Humanas, Letras e Artes, Universidade Federal do Paraná. Curitiba, 2014.

SEMPOL, Diego. Autoritarismos morais, dissidência sexual e memória: ditaduras civil-militares na Argentina e no Uruguai e organizações LGTTBIQ. In: QUADRAT, 
Samantha; ROLLEMBERG, Denise (Orgs.). História e memória das ditaduras do século XX. Vol. 2. Rio de Janeiro: Editora FGV, 2015. p. 163-197.

SERVIÇO NACIONAL DE INFORMAÇÕES. Fatores que influem na formação da moral social e da opinião pública brasileira, p. 1 a 10. (Arquivo Nacional, Distrito Federal). 30/04/1980a.

SERVIÇO NACIONAL DE INFORMAÇÕES. Fatores que influem na formação da moral social e da opinião pública brasileira. APA/ACE/CNF 1825/80, p. 1 a 20. (Arquivo Nacional, Distrito Federal). 28/10/1980b.

SERVIÇO NACIONAL DE INFORMAÇÕES. Residência Universitária/UFBA, p. 1 a 5 (Arquivo Nacional, Distrito Federal). 24/11/1980c.

SIRINELLI, Jean-François. Abrir a história: novos olhares sobre o século XX francês. Belo Horizonte: Autêntica Editora, 2014.

SONTAG, Susan. Doença como metáfora: AIDS e suas metáforas. São Paulo: Companhia das Letras, 2007.

SOUZA, Sandra Regina B. da Silva. O "monstro cheio de tentáculos" nas ficções do Coronel Ferdinando de Carvalho sobre o comunismo e o PCB durante a ditadura civil-militar. In: CARDOSO, Lucileide; CARDOSO, Célia. Ditaduras: memória, violência e silenciamento. Salvador: EDUFBA, 2017. p. 401-426.

SUBVERSÃO, TERRORISMO... Subversão, Terrorismo e Narcotráfico na América Latina. Tóxicos, p. 1 a 2 (Arquivo Nacional, Distrito Federal).

YOUNG, Robert J. C. Disseminating the Tricontinental. In: CHEN, Jian; KLIMKE, Martin; KIRASIROVA, Masha; NOLAN, Mary; YOUNG, Marilyn; WALEY-COHEN, Joanna. The Routledge handbook of the global sixties: between protest and nation-building. Abingdon, Oxon; New York, NY: Routledge, 2018. p. 517-547. VELHO, Gilberto. Individualismo e cultura: Notas para uma Antropologia da Sociedade Contemporânea. Rio de Janeiro: Zahar Editores, 1987.

\section{NOTA}

${ }^{1}$ Este texto é fruto do Estágio Pós-Doutoral 2018/2019 desenvolvido na Universidade Federal de Minas Gerais e na Universidade do Porto. Grato a Rodrigo Patto Sá Motta e a Manuel Loff pelo acolhimento e diálogos, bem como aos pareceristas anônimos da Revista Brasileira de História pelos comentários. Os eventuais equívocos e lacunas são de responsabilidade exclusiva do autor.

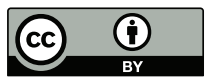

Artigo recebido em 15 de novembro de 2019. Aprovado em 11 de setembro de 2020. 